\title{
Emergency Department Visits and Injury Hospitalizations for Female and Male Victims and Perpetrators of Intimate Partner Violence
}

\author{
Catherine L. Kothari, ${ }^{1}$ Thomas Rohs, ${ }^{2}$ Scott Davidson, ${ }^{3}$ Rashmi U. Kothari, ${ }^{4}$ Carrie Klein, \\ Amy Koestner, ${ }^{6}$ Mican DeBoer, ${ }^{7}$ Rita Cox,${ }^{3}$ and Kim Kutzko ${ }^{1}$ \\ ${ }^{1}$ Biomedical Department, Western Michigan University Homer Stryker M.D. School of Medicine, 1000 Oakland Drive, \\ Kalamazoo, MI 49008, USA \\ ${ }^{2}$ Trauma Department, Borgess Medical Center, Kalamazoo, MI 49048, USA \\ ${ }^{3}$ Trauma Department, Bronson Methodist Hospital, Kalamazoo, MI 49007, USA \\ ${ }^{4}$ Emergency Medicine Department, Borgess Medical Center, Kalamazoo, MI 49048, USA \\ ${ }^{5}$ Kalamazoo County Prosecuting Attorney's Office, Kalamazoo, MI 49001, USA \\ ${ }^{6}$ Trauma Department, Spectrum Health Butterworth, Grand Rapids, MI 49503, USA \\ ${ }^{7}$ Emergency Department, Bronson Lakeview Hospital, Kalamazoo, MI 49048, USA
}

Correspondence should be addressed to Catherine L. Kothari; catherine.kothari@med.wmich.edu

Received 29 August 2015; Revised 26 October 2015; Accepted 27 October 2015

Academic Editor: Bruno Megarbane

Copyright (C) 2015 Catherine L. Kothari et al. This is an open access article distributed under the Creative Commons Attribution License, which permits unrestricted use, distribution, and reproduction in any medium, provided the original work is properly cited.

\begin{abstract}
Introduction. The potential for hospital-based interventions for male victims of intimate partner violence (IPV) as well as adult perpetrators of both genders has been largely unexplored despite early evidence of acute-care utilization that may be as high as female victims. The current investigation compared the emergency department (ED) and injury-related-hospitalization rates of IPV-involved individuals against standardized national norms, assessing differences by gender and victim/perpetrator-status. Methods. This cross-sectional study collected one-year ED and in-patient visit data from hospital records for individuals listed as victim or perpetrator in an IPV criminal charging request in a Midwestern county $(N=2,937)$. Expected rates were calculated based upon age-adjusted national norms. Results. The IPV-involved population generated ED rates 4.1 times higher than expected and injury-related-hospitalization rates that were 4.0 times higher than expected. Bi-directionally-violent individuals (both victim and perpetrator in IPV charges) consistently had the highest utilization rates (ED 8.4 RR, injury-hospitalization 22.5 RR). Victims, primarily female, had higher ED-visits than perpetrators, primarily male (victims $=4.6 \mathrm{RR}$, perpetrator $=3.1 \mathrm{RR}$ ). Perpetrators, though, had higher injury hospitalizations (victims $=0.8 \mathrm{RR}$, perpetrators $=5.5 \mathrm{RR}$ ). Conclusions. Substantial opportunities exist within acute-care medical settings to intervene with IPV-involved women, men, victims, and perpetrators, although the magnitude of the opportunity varied by setting, gender and victim/perpetrator-status.
\end{abstract}

\section{Introduction}

The presence of female intimate partner violence (IPV) victims within healthcare settings and the ability of trained, supported providers to detect them have been well documented [1-3]. Healthcare identification, in turn, has the potential to link victims to community services through referrals to shelters, victim advocates, legal services, and counseling [46]. Such services have been shown to improve psychological health and social support and, in the case of postshelter advocacy and perinatal home visitation, to reduce violence [7-10]. However, much of the hospital-based research to date has focused upon universal screening in emergency departments, with little evidence that this has translated to service uptake, greater safety, or subsequent well-being [1116]. Studies have reported that the logistical constraints common to emergency departments present significant barriers to effective screening [17-20]. IPV interventions that target 
hospitalized rather than ambulatory-care patients may hold more promise given their greater time, space, and privacy, yet the possible yield from expanding the existing hospital-based violence-prevention lens has remained largely unexplored.

Similarly, male victims and IPV perpetrators of either gender have, to date, received scant attention within the healthcare field [21-23]. The near-exclusive focus upon female victims has been motivated by the higher rates of injury and long-term morbidity from IPV assaults that are consistently recorded for female victims [24-29]. Reports that male victims' and perpetrators' healthcare utilization may be as high as female victims [30-33], however, coupled with the growing efficacy of therapeutic interventions targeting male perpetrators [34-39], point to the potential of healthcarebased IPV interventions targeting these populations. Further, studies have observed that female victims' own use of aggression may be associated with greater violence and injury $[40,41]$, a feature that has not been explicitly integrated into injury prevention programs [42].

In a systematic examination of medical care utilization that crosses victim/perpetrator status and gender lines as well as acute care settings, the current investigation examined the relative potential for identification and intervention from the emergency department and medical-surgical settings for all IPV-involved individuals: women, men, victims, and perpetrators. Specifically, the objectives of this paper were as follows:

(1) To compare actual rates of emergency department visits and injury-related hospitalizations by IPVinvolved individuals against expected, nationally normed rates.

(2) To determine the variation in volume and rates associated with gender and victim/perpetrator status regarding emergency department visits and injuryrelated hospitalizations.

\section{Methods}

This study utilized an observational, cross-sectional design to determine the actual and expected rates of ED visits and injury-related hospitalizations by IPV-involved individuals in Kalamazoo County, Michigan, occurring in the year 2010. Actual visit rates were calculated using national visit-standardization algorithms [43, 44]. Data collection, completed in 2012-2013, involved exporting hospital and prosecutor datasets from administrative records. Permission to access data was provided by Michigan Department of Community Health and Kalamazoo County Michigan Office of the Prosecuting Attorney. Institutional Review Board approval and HIPAA exemption were provided by the Michigan Department of Community Health, Borgess Medical Center, and Bronson Methodist Hospital.

2.1. Study Sample. The study population consisted of the 2,937 individuals who were named as a victim or a perpetrator, an IPV-related criminal charging request submitted to Kalamazoo County Prosecutor's Office in 2010. As depicted in Figure 1, the 1,807 charging request incidents (assault and nonassault) where the victim and the perpetrator had an intimate relationship (current or former spouse, dating partner, homosexual partner, or a child in common) were exported from the Kalamazoo County Prosecuting Attorney's Office. First, all perpetrator and victim names that were listed in the charging requests were extracted, totaling 3,614 names (two for each incident). Then, duplicates, a product of individuals being involved in multiple charging requests, were removed. The only exclusion criterion was perpetrator of age 17 or under. Individuals were categorized into three types based upon the nature of their involvement in study charging requests: victim only, perpetrator only, or bidirectional (the individual was named as both a victim and a perpetrator in one or more charging requests).

The study site, Kalamazoo County, is located in southwest Michigan, with a 2010 population of 250,331 [45], and is comparable to the nation regarding poverty level $(22.1 \%$ versus $25.6 \%$, US) [46], crime rate (428.2 violent crimes per 100,000 residents versus 410.9, US) [47], and acute care capacity (2.3 acute care hospital beds per 1,000 residents versus 2.4 , US) $[48,49]$ but with fewer minority residents (18.3\% versus $27.6 \%$, US) and fewer family-type households (59.9\% versus $66.4 \%$, US) [45]. In 2010, Kalamazoo County housed two Trauma I Centers, one at Borgess Medical Center and one at Bronson Methodist Hospital, which, together, served a nine-county region in southwest Michigan.

2.2. Data Collection. Study data consisted of administrative records exported from three sources: crime data from Kalamazoo County MI Prosecuting Attorney's Office and hospital data from Borgess Medical Center and Bronson Methodist Hospital, both Trauma I Centers. Crime data collection, in addition to producing the study sample described above, included demographic variables (gender, race, and age), victim-perpetrator relationship variables, and criminal incident descriptors (charge, whether drugs or alcohol was noted as contributing factors to the incident, the charge disposition, and victim injury (minor, defined as scratches or bruises, and major, such as broken bones, loss of consciousness, and internal injury)). It is worth noting that, as noncritical and often nonavailable data fields within the prosecutor's administrative records system, there was a substantial amount of missing information for the injury, drug/alcohol, and prior history of IPV variables.

Hospital data was produced by the Health Information Management departments within each of the two study hospitals. The Health Information Management departments exported records for all individuals who were emergency department patients in 2010, aged twelve or more. Study investigators compiled these records into a single dataset of 89,500 individuals. As shown in Figure 1, a linking process was then conducted to identify individuals who appeared in both the IPV-crime population and the ED population. ED patients, stratified into IPV-crime-involved and non-IPVcrime-involved, and their associated $2010 \mathrm{ED}$ visits formed the basis for study prevalence and incidence and standardized visit rates. Additional hospital variables included whether the visit was injury-related or not (as defined by diagnosis ICD-9 codes 800-959.9) and whether the ED visit led to an injuryrelated hospital admission or not. 


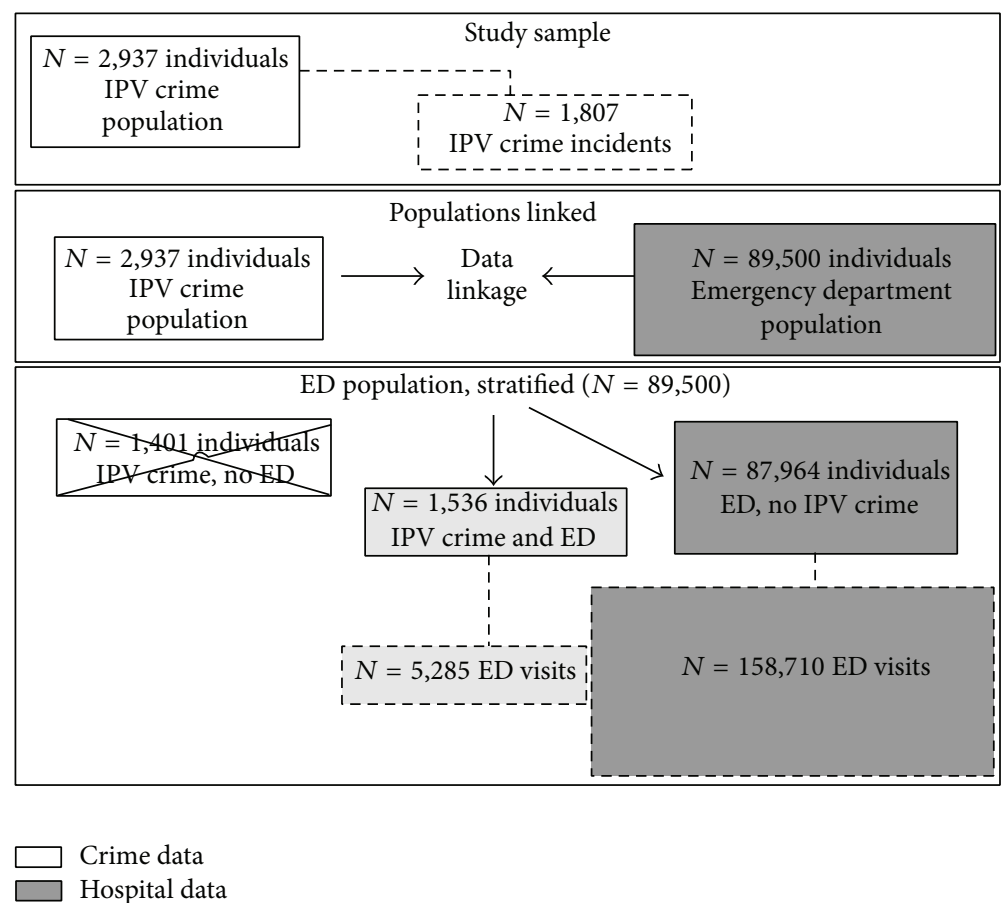

FIGURE 1: Flow chart of study sample, linkage, and stratified emergency department groups.

2.2.1. Linkage Procedures. Data matching was completed with LinkPlus, a software program developed by the US Centers for Disease Control and Prevention that utilizes probabilistic record linkage for matching alphanumeric identifiers across datasets. For the study, person-level matching was conducted using first name, last name, and date of birth. In order to determine the most effective parameters for the probabilistic algorithm and to assess the quality of the final electronic linkage, the following steps were completed:

(1) A gold-standard-match dataset was created by manually abstracting emergency department records directly from hospital electronic records systems for a subset of the IPV-crime population (200 randomly selected individuals).

(2) Multiple iterations of the crime/hospital linkage were performed, using various algorithm values, until a linked dataset was produced that contained the greatest number of gold-standard records. These algorithm parameters were then adopted for the full, final linkage.

(3) To assess linkage quality, LinkPlus was run, using the adopted parameters, with the 200-person subset, and the results were compared against the gold-standardmatch. Results showed (a) there were no false-positive matches and (b) there were 9.3\% false-negatives. In other words, $90.7 \%$ of the time, ED records associated with an IPV-involved study participant were accurately captured using the study linkage procedures.

Within linked individuals, event-level matching was based upon incident-date variables in the crime and hospital datasets (e.g., date of crime and date of ED visit) and was conducted using SPSSv.20.
2.2.2. Measures and Rate Calculations. ED visits and injuryrelated hospitalizations for the cohort of IPV-involved individuals were reported as counts and as population rates. Volume was defined as summed total counts for the year 2010. Rates were computed as defined below:

(i) Actual visit rates were computed using the same algorithm as that employed to standardize national rates $[43,44]$ : ED visits [(number of visits)/(total population $) * 100$ individuals] and hospitalizations [(number of hospitalizations)/(total population) * 10,000 individuals].

(ii) Expected ED visit rates were calculated using the National Hospital Ambulatory Medical Care 2010 emergency department summary tables. Expected rates for the injury-related hospitalizations were calculated using the National Center for Health Statistics rates of discharges from short-stay hospitals in 2010, the ICD-9-CM diagnosis category for injury and poisoning (ICD-9-CM 800-999) excluding poisonings (ICD-9-CM 960-989) and complications (ICD9-CM 996-999).

(a) Age Adjustment. Expected rates, both ED and injury-related hospitalizations, were adjusted for the age distribution of the study sample using national age-groupings and the indirect method of adjustment $[43,44]$.

2.3. Statistical Analysis. Descriptive statistics were reported for sample demographics, crime-incident characteristics, and acute care visit characteristics. Statistical analyses compared demographics across victim/perpetrator status groups using 
TABLE 1: Characteristics of IPV-involved individuals, stratified by IPV victim/perpetrator status.

\begin{tabular}{|c|c|c|c|c|c|}
\hline & \multirow{2}{*}{$\begin{array}{c}\text { Total IPV-involved } \\
\text { individuals }(N=2,937) \\
\%(\#)\end{array}$} & \multicolumn{4}{|c|}{ Victim/perpetrator status during 2010} \\
\hline & & $\begin{array}{c}\text { Victim only } \\
(N=1,419) \\
\%(\#)\end{array}$ & $\begin{array}{c}\text { Perpetrators only } \\
(N=1,387) \\
\%(\#)\end{array}$ & $\begin{array}{c}\text { Bidirectional } \\
(N=131) \\
\%(\#)\end{array}$ & $p$ value $^{\mathrm{a}}$ \\
\hline \multicolumn{6}{|l|}{ Gender } \\
\hline Female & $50.4(1445)$ & 78.8 (1078) & $21.6(295)$ & $55.4(72)$ & \multirow{3}{*}{$<.001$} \\
\hline Male & $49.6(1420)$ & $21.2(290)$ & $78.4(1072)$ & $44.6(58)$ & \\
\hline [Missing] & [72] & [51] & [20] & [1] & \\
\hline \multicolumn{6}{|l|}{ Race } \\
\hline White & $53.2(1431)$ & $55.8(702)$ & $50.3(661)$ & $55.7(68)$ & \multirow{4}{*}{.013} \\
\hline Black & $45.2(1218)$ & $42.2(530)$ & $48.3(634)$ & $44.3(54)$ & \\
\hline Other & $1.6(43)$ & $2.0(25)$ & $1.4(18)$ & $-(0)$ & \\
\hline [Missing] & {$[245]$} & [162] & {$[106]$} & [9] & \\
\hline \multicolumn{6}{|l|}{ Age (years) } \\
\hline$<25$ & $33.1(947)$ & 34.9 (468) & $31.1(431)$ & $36.6(48)$ & \multirow{5}{*}{.093} \\
\hline $25-30$ & $20.3(581)$ & $20.8(279)$ & $19.7(273)$ & $22.1(29)$ & \\
\hline $31-40$ & $24.0(686)$ & $23.0(309)$ & $25.6(355)$ & $16.8(22)$ & \\
\hline$>40$ & $22.5(644)$ & $21.3(285)$ & $23.6(327)$ & $24.4(32)$ & \\
\hline [Missing] & [79] & {$[78]$} & {$[1]$} & {$[0]$} & \\
\hline Average \# of IPV incidents in 2010 (SD) & $1.24(0.62)$ & $1.16(0.50)$ & $1.19(0.54)$ & $2.61(0.93)$ & $<.001$ \\
\hline Range in \# of incidents in 2010 & 1 to 6 & 1 to 6 & 1 to 6 & 2 to 6 & NA \\
\hline$\%$ with multiple IPV incidents & $16.8(493)$ & $11.8(167)$ & $14.1(195)$ & $100(131)$ & $<.001$ \\
\hline
\end{tabular}

${ }^{a}$ Percentages and $p$ values based upon valid, nonmissing responses.

Boldface indicates statistical significance $(p \leq .05)$.

Pearson Chi-Square test for nominal data and ANOVA, with Bonferroni correction, for continuous count variables. Rates of expected ED visit and injury hospitalizations were compared against actual rates, between victim/perpetrator status groups, and for ED visits, by gender. Rate comparisons were conducted using multiple $t$-tests, corrected with Bonferroni. Significance tests were two-tailed with a significance level of 0.05. Analysis, conducted in 2012-2013, was completed using SPSSv.20.

\section{Results}

3.1. Sample Characteristics. The 2,937 study individuals were involved in a total of 1,807 separate IPV criminal incidents during the study year 2010. As seen in Table 1 , a minority of individuals $(16.8 \%, n=493)$ were involved in multiple incidents. An even smaller group, 4.5\% $(n=131)$, were alternately the victim and the perpetrator in these crimes, meeting study criteria for bidirectional violence; twenty-four of these had dual-arrest incidents, where police could not identify a primary aggressor and thus submitted charging requests against both individuals for the same incident. In general, females predominated as the victims and males as the perpetrators, except for the bidirectional group, where gender split was more equal.
At the time of the IPV-crime incident, the majority of couples were unmarried and still together and had experienced prior violence, as reported by the victim (see Table 2). Severe violence, indicated by charges of aggravated assaults, sexual assault, or kidnapping, accounted for $5.5 \%$ of incidents. The available information on victim injury demonstrated the relative minor nature of most assaults; although with the large amount of missing data, this conclusion is a tentative one.

Incidents involving bidirectional individuals were associated with higher rates of reported prior violence $(92.0 \%$, $p<.001$, not shown) and moderately higher levels of victim injury (74.2\% minor injury and 3.2\% major injury, $p<.001$, not shown). Significantly fewer cases involving bidirectional individuals were prosecuted: $34.1 \%, 147$ of 223 , of incidents were accepted for prosecution compared to $49.9 \%, 906$ of 1807 , of cases overall ( $p<.001$, not shown).

3.2. Volume of Emergency Department Visits and InjuryRelated Hospitalizations. As depicted in Table 3, among the 2,937 IPV-involved samples, $52.3 \%$ had at least one ED visit during 2010, the year their known IPV crime occurred. The number of ED visits by these individuals ranged from 1 to 77 visits and averaged significantly higher than non-IPV patients (mean of 3.44 visits (CI 3.20 and 3.69) for IPV-involved ED 
TABLE 2: Characteristics of IPV charging request incidents, 2010.

\begin{tabular}{|c|c|}
\hline & $\begin{array}{c}\text { Total IPV incidents during } \\
\text { study period }^{\mathrm{a}} \\
(N=1,807) \\
\%\end{array}$ \\
\hline \multicolumn{2}{|l|}{ At time of incident } \\
\hline \multicolumn{2}{|l|}{ Marital status } \\
\hline Married & $21.4(348)$ \\
\hline [Missing] & {$[180]$} \\
\hline \multicolumn{2}{|l|}{ Relationship status } \\
\hline Together & $83.7(1361)$ \\
\hline [Missing] & {$[180]$} \\
\hline \multicolumn{2}{|l|}{ Previous IPV } \\
\hline Yes & $82.8(515)$ \\
\hline [Missing] & {$[1,185]$} \\
\hline \multicolumn{2}{|l|}{ Incident } \\
\hline \multicolumn{2}{|l|}{ Charge category } \\
\hline Assault (simple) & $81.3(1,453)$ \\
\hline Stalking/harassment & $4.9(88)$ \\
\hline Nonassault (property, etc.) & $5.0(89)$ \\
\hline Aggravated assault & $4.8(86)$ \\
\hline PPO violation & $2.6(47)$ \\
\hline Criminal sexual cond. & $0.5(9)$ \\
\hline Child abuse & $0.5(9)$ \\
\hline Kidnapping & $0.3(6)$ \\
\hline Cruelty to animals & $0.1(1)$ \\
\hline [Missing] & [19] \\
\hline \multicolumn{2}{|l|}{ Victim injury } \\
\hline None noted & $27.8(207)$ \\
\hline Minor injury & $69.5(517)$ \\
\hline Major injury & $2.6(19)$ \\
\hline Fatal injury & $0.1(1)$ \\
\hline [Missing] & {$[1,063]$} \\
\hline \multicolumn{2}{|l|}{ Victim transported to hospital } \\
\hline No & $87.2(622)$ \\
\hline Yes & $12.8(91)$ \\
\hline [Missing] & {$[1,094]$} \\
\hline \multicolumn{2}{|l|}{ Drug/alc. involvement } \\
\hline No & $44.9(265)$ \\
\hline Yes & $55.1(325)$ \\
\hline [Missing] & {$[1,217]$} \\
\hline \multicolumn{2}{|l|}{ Charge class } \\
\hline Civil & $2.6(47)$ \\
\hline Misdemeanor & $86.2(1557)$ \\
\hline Felony & $11.2(203)$ \\
\hline \multicolumn{2}{|l|}{ Defendant disposition } \\
\hline Denied & $50.1(906)$ \\
\hline Dismissed & $17.2(311)$ \\
\hline Pled lesser & $4.6(83)$ \\
\hline Convicted & $25.6(462)$ \\
\hline Not guilty & $0.3(5)$ \\
\hline Open & $2.2(40)$ \\
\hline
\end{tabular}

${ }^{\mathrm{a}}$ Percentages values based upon valid, nonmissing responses. patients and mean of 1.78 visits (CI 1.76 and 1.79) for nonIPV-involved ED patients). In sum, the number of ED visits generated by the IPV-involved sample ( $N=5,285$ visits) represented 3.2\% of the total 163,995 visits by all patients in 2010. Despite higher volume and known exposure to physical violence, though, IPV-involved patients were no more likely to present to the ED with an injury complaint than non-IPV patients and were significantly less likely to be hospitalized for an injury. Further, the vast majority of ED visits did not occur the same day as the known IPV crime; those that did were much more likely to be for injury complaints $(69.0 \%$ of same-day visits compared to $19.0 \%$ of total visits, $p<.001$, not shown). Finally, among the victim/perpetrator status groups, bidirectional individuals had the highest ED utilization, the most injury-related ED visits, the greatest likelihood of an ED visit on the same day as a known IPV crime, and the greatest likelihood of hospitalization.

Table 3 further shows that injury-related hospitalizations were rare events, even among the IPV population, with only $0.4 \%$ of the total ED visits during 2010 leading to an injuryrelated admission. Just a portion of these $(25.0 \%)$ occurred on the same day as the IPV crime.

3.3. Rates of Emergency Department Utilization. As illustrated in Table 4, IPV-involved individuals had actual annual visit rates that were more than 4 times higher than the expected age-adjusted rate, based upon national utilization calculations: 179.9 per 100 persons actual visit rates compared to 44.0 per 100 persons expected ED visit rate. Females, regardless of IPV involvement, had significantly higher ED visit rates than males, with Relative Risk of 4.5 for females and Relative Risk of 3.5 for males (not shown), a disparity that held true across the three victim/perpetrator status groups. Beyond this gender effect, ED utilization varied strongly by victim/perpetrator status: bidirectional individuals had the highest rates, followed by victim-only individuals and, lastly, perpetrator-only individuals.

3.4. Rates of Injury-Related Hospitalization. Hospitalization was a low-base rate phenomenon, with only 5 hospitalizations expected for this relative young population (77.5\% under age 40). As a result, the confidence intervals around hospitalization rates were quite broad, especially in the subgroup analysis. Nonetheless, a pattern similar to the ED utilization emerged. Actual rates of injury-related hospitalizations by IPV-involved individuals, 68.1 hospitalizations per 10,000 persons, were statistically significantly higher than the expected rate of 17.0 per 10,000 persons, by a ratio similar to ED utilization: Relative Risk of 4.0. Victim/perpetrator status, again, was associated with differential utilization, with bidirectional individuals having the highest rates, although the difference was not statistically significant once corrected with Bonferroni for multiple comparisons. Unlike ED visits, though, victim-only and perpetrator-only rates flipped. With hospitalization rates of 14.1 per 10,000 persons during 2010, victim-only individuals had the lowest rates of injury-related hospitalization, during the year of the police-identified IPV crime. Perpetrator-only individuals, on the other hand, had significantly higher hospitalization, with an annual rate of 


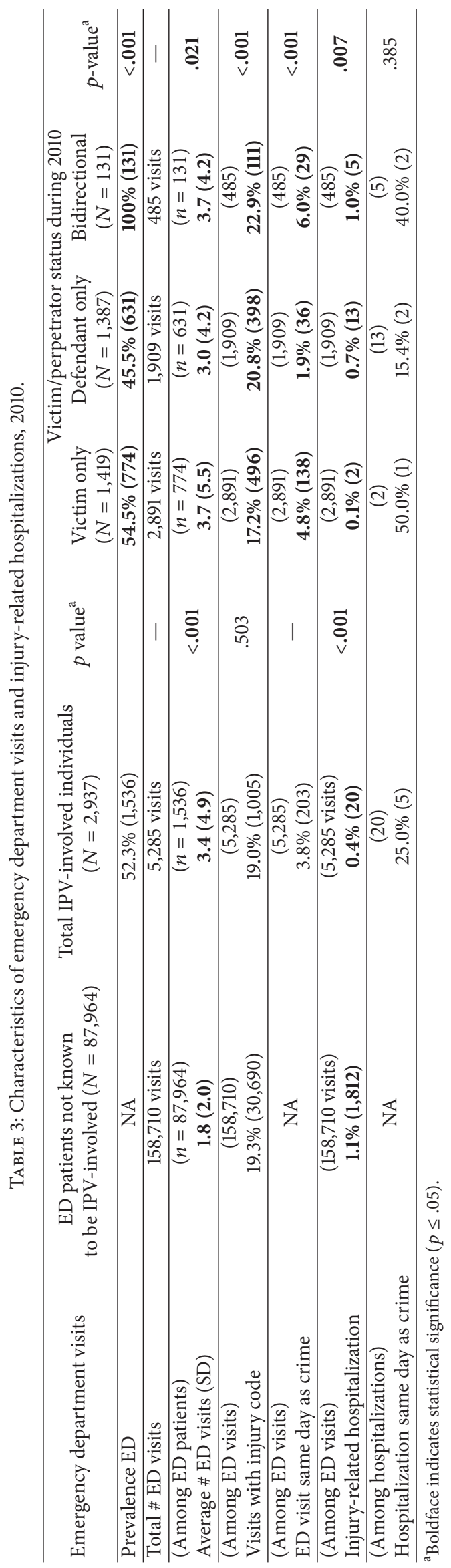




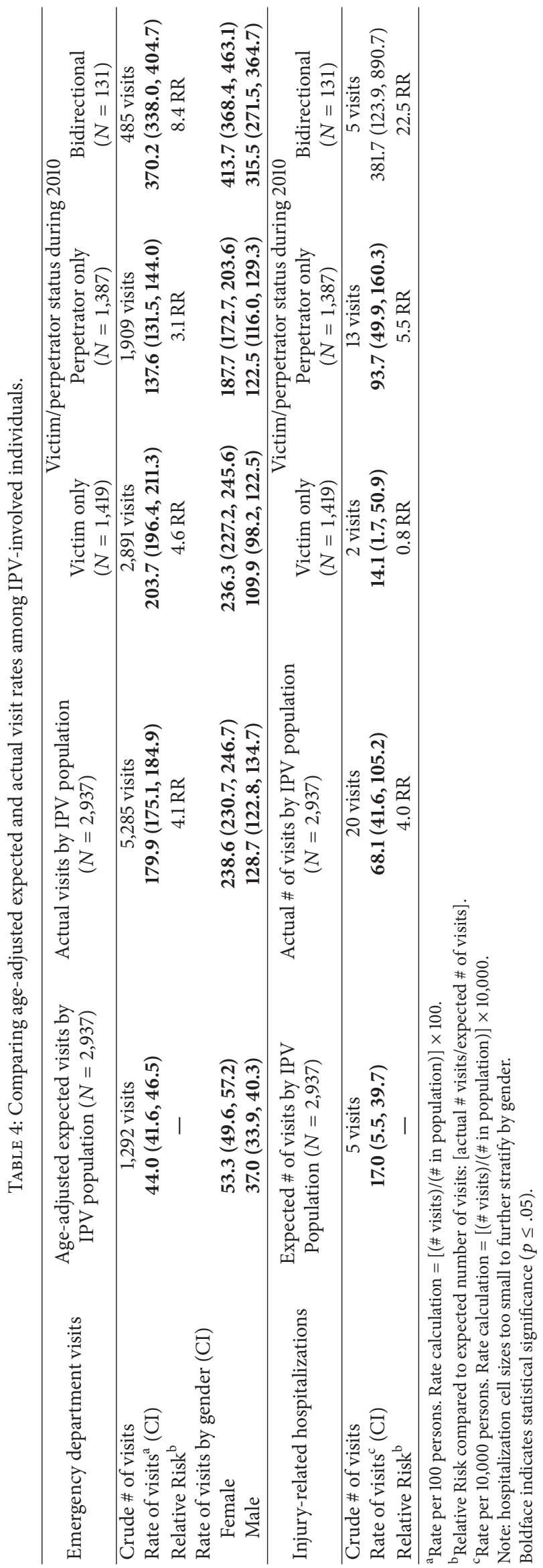


93.7 per 10,000 persons during the same year as their IPV perpetration, 2010.

\section{Discussion}

Compared to national rates, the IPV-involved study sample had four times higher rates of ED visits and injury-related hospitalizations. More than half of the sample had visited an ED at least once during the year of the IPV crime, although only a handful of ED visits occurred on the same day as the known crime and rarely led to injury-related hospitalizations. This study further demonstrated that gender differences were more marked than among non-IPV-involved ED patients and that patterns of utilization varied by victim/perpetrator status and differentially between acute care settings. Conducted in a community with poverty, crime, and acute care capacity comparable to the nation, study findings add to the literature by documenting that the high utilization well-known for female IPV victims [1, 22, 50-52] was also true for male victims and for perpetrators of both genders.

This study is one of the first to clearly identify that bidirectionally violent individuals had the highest levels of both ED visits and injury-related hospitalizations, regardless of their gender. Outside healthcare, the IPV literature has detailed a variety of scenarios that can lead to bidirectional violence, including sparring between equal partners, strong mutual aggression, and systemic one-sided abuse where the victim has resorted to violence in self-defense [53, 54]. Regardless, the higher acuity of these cases, within this study and documented in others $[32,55]$, highlights the significance of bidirectional violence as a strong marker of injury risk and subsequent trauma care. This is particularly significant when considering that these cases are often dropped by criminal courts, the mutuality of violence making them difficult to prosecute [56]. Within the healthcare system, policies promoting screening exclusively for victimization but not perpetration [57] may also be missing the mark, as knowing which victims are also perpetrators could help triage them into high priority for community service referrals and safety planning, interventions they may not be getting within the criminal justice system.

Two other patterns revealed by study comparisons were the relatively high ED utilization by female victims and high injury-related hospitalization of perpetrators. While females tend to generate more ED visits than males across the nation [44], the elevated rate and volume of ED visits by IPV victims are consistent with prior literature documenting their greater injury $[22,29]$, the significant long-term physical and mental health sequelae associated with IPV [24, 50], and their high rates of medical help-seeking within EDs as well as primary care settings $[22,24,32,50]$. The relatively lower visit rates by male victims are congruent with estimates of lower IPV-injury among this population [22]. The heightened rate by victims of both genders spotlights the opportunities which are clearly present in the ED for identification and linkage to community resources and suggests that these efforts be extended to include male victims. Given that the study measure of IPV was based upon criminal justice identification, a situation which applies to, at best, half of all
IPV couples [56], and that clinic-based studies have reported higher levels of IPV victimization than detailed in the current study, the true extent of these opportunities is likely even greater.

The picture emerging regarding hospitalizations by perpetrator-only individuals, a predominantly male group, was that they led victims in injury-related hospitalizations, both in volume and in comparison with age-matched national rates. While limited in number, other studies of injury-related medical hospitalizations by male perpetrators point to a different injury-related etiology than that of female victims: that individuals, such as IPV perpetrators, who are violent inside the home are also violent outside of it and that injuries leading to medical care are often inflicted by nonpartners, sometimes in the course of the perpetrator's own assaultive behavior [30, 33, 58-60]. The female-victim hospitalization levels found in this study are similar to national population studies and reflect the relatively minor nature of most IPV physical injuries $[22,61,62]$. Similar to ED visits, these low figures, however, likely undercount the actual presence of female victims on medical-surgical floors, which hospitalbased surveys have found to be as high as that in EDs, up to $15 \%$ of patients $[1,2,63]$.

\section{Limitations}

These findings should be viewed in light of the following study limitations. Due to concerns with safety, privacy, and stigma, IPV victims may not report assaults to police or seek medical care, which means this IPV study population, defined by both police and ED usage, may be a biased group, albeit one likely representing greater violence and severity [56, 64]. Additionally, operationalizing IPV as policeidentified IPV crime, while narrowing the study sample, offers the advantage of an external measure that is not dependent upon either injury presentation to the ED or selfdisclosure by a patient, common alternatives that can produce significant bias. As a geographically bound study, there is a chance that ED visits or IPV crimes involving the study population may have occurred outside the Kalamazoo County area and, thus, were not captured. With a $90.7 \%$ true-positive match rate, the linkage process did not identify roughly ten percent of ED visits, resulting in a conservative estimate of utilization. Additionally, as a secondary data analysis with low same-day visit incidence and a large amount of missing crime data on victim injury, the study was lacking important information connecting specific IPV assaults to injury and subsequent medical visits, leaving such relationships to be inferred. Finally, the demographic profile of the study site regarding racial composition and household type, different from the nation as a whole, may limit its generalizability.

\section{Conclusions}

This study documents that elevated emergency department visits and injury-related hospitalization exit for all IPVinvolved individuals, with the highest rates by bidirectionalviolence individuals and differential utilization by victim/perpetrator status, depending upon acute care setting. 


\section{Disclosure}

Borgess Medical Center, Kalamazoo, Michigan, had no role in study design, collection, analysis, data interpretation, paper preparation, or the publication decision.

\section{Conflict of Interests}

The authors have no known conflict of interests regarding the content or findings contained within this paper. The study authors do not have any commercial association, current or over the past five years, that might pose a conflict of interests.

\section{Acknowledgments}

Borgess Medical Center, Kalamazoo, Michigan, provided financial support for the data collection and analysis of this study. The authors would like to acknowledge the guidance and support of the Michigan Department of Community Health, Crime Victims, EMS \& Trauma System Division, and further sincerely thank Karin V. Rhodes, University of Pennsylvania, and Sherry VandenBerg, Bronson Methodist Hospital, for their invaluable scientific expertise and advice.

\section{References}

[1] J. Abbott, R. Johnson, J. Koziol-McLain, and S. R. Lowenstein, "Domestic violence against women: incidence and prevalence in an emergency department population," Journal of the American Medical Association, vol. 273, no. 22, pp. 1763-1767, 1995.

[2] S. R. Dearwater, J. H. Coben, J. C. Campbell et al., "Prevalence of intimate partner abuse in women treated at community hospital emergency departments," The Journal of the American Medical Association, vol. 280, no. 5, pp. 433-438, 1998.

[3] L. J. O’Doherty, A. Taft, K. Hegarty, J. Ramsay, L. L. Davidson, and G. Feder, "Screening women for intimate partner violence in healthcare settings: abridged Cochrane systematic review and meta-analysis," British Medical Journal, vol. 348, Article ID g2913, 2014.

[4] B. Ambuel, M. B. Phelan, L. K. Hamberger, and D. Wolff, "Healthcare can change from within: a sustainable model for intimate partner violence prevention and intervention," in Trauma and Physical Health: Understanding the Effects of Extreme Stress and of Psychological Harm, V. Banyard, V. Edwards, and K. Kendall-Tackett, Eds., p. 202, Routledge, New York, NY, USA, 2009.

[5] G. Feder, C. N. Wathen, and H. L. MacMillan, "An evidencebased response to intimate partner violence: WHO guidelines," The Journal of the American Medical Association, vol. 310, no. 5, pp. 479-480, 2013.

[6] B. McCaw, W. H. Berman, S. L. Syme, and E. F. Hunkeler, "Beyond screening for domestic violence: a systems model approach in a managed care setting," American Journal of Preventive Medicine, vol. 21, no. 3, pp. 170-176, 2001.

[7] D. Bybee and C. M. Sullivan, "Predicting re-victimization of battered women 3 years after exiting a shelter program," American Journal of Community Psychology, vol. 36, no. 1-2, pp. 85-96, 2005.

[8] R. Constantino, Y. Kim, and P. A. Crane, "Effects of a social support intervention on health outcomes in residents of a domestic violence shelter: a pilot study," Issues in Mental Health Nursing, vol. 26, no. 6, pp. 575-590, 2005.

[9] N. J. Kaslow, A. S. Leiner, S. Reviere et al., "Suicidal, abused African American women's response to a culturally informed intervention," Journal of Consulting and Clinical Psychology, vol. 78, no. 4, pp. 449-458, 2010.

[10] P. Sharps, L. Bullock, J. Alhusen, S. Ghazarian, D. Schminkey, and J. Campbell, "DOVE-a nurse home visitation intervention to reduce violence against pregnant women: a randomized clinical trial," in American Public Health Association 142nd Annual Meeting \& Expo, 2014.

[11] C. I. Eckhardt, C. M. Murphy, D. J. Whitaker, J. Sprunger, R. Dykstra, and K. Woodard, "The effectiveness of intervention programs for perpetrators and victims of intimate partner violence," Partner Abuse, vol. 4, no. 2, pp. 196-231, 2013.

[12] J. Koziol-McLain, N. Garrett, J. Fanslow et al., "A randomized controlled trial of a brief emergency department intimate partner violence screening intervention," Annals of Emergency Medicine, vol. 56, no. 4, p. 413, 2010.

[13] H. L. MacMillan, C. N. Wathen, E. Jamieson et al., "Screening for intimate partner violence in health care settings: a randomized trial," Journal of the American Medical Association, vol. 302, no. 5, pp. 493-501, 2009.

[14] J. McFarlane, K. Soeken, S. Reel, B. Parker, and C. Silva, "Resource used by abused women following an intervention program: associated severity of abuse and reports of abuse ending," Public Health Nursing, vol. 14, no. 4, pp. 244-250, 1997.

[15] R. L. Muelleman and K. M. Feighny, "Effects of an emergency department-Based advocacy program for battered women on community resource utilization," Annals of Emergency Medicine, vol. 33, no. 1, pp. 62-66, 1999.

[16] K. V. Rhodes, C. Cerulli, C. L. Kothari, M. E. Dichter, and S. Marcus, "Victim participation in intimate partner violence prosecution: implications for safety," Tech. Rep. Doc \#235284, US Department of Justice, National Institute of Justice, Washington, DC, USA, 2011.

[17] D. Anglin and C. Sachs, "Preventive care in the emergency department: screening for domestic violence in the emergency department," Academic Emergency Medicine, vol. 10, no. 10, pp. 1118-1127, 2003.

[18] D. Minsky-Kelly, L. K. Hamberger, D. A. Pape, and M. Wolff, "We've had training, now what? Qualitative analysis of barriers to domestic violence screening and referral in a health care setting," Journal of Interpersonal Violence, vol. 20, no. 10, pp. 1288-1309, 2005.

[19] P. R. Salber and B. McCaw, "Barriers to screening for intimate partner violence: time to reframe the question," American Journal of Preventive Medicine, vol. 19, no. 4, pp. 276-278, 2000.

[20] S. Sprague, K. Madden, N. Simunovic et al., "Barriers to Screening for Intimate Partner Violence," Women and Health, vol. 52, no. 6, pp. 587-605, 2012.

[21] C. S. Stover, A. L. Meadows, and J. Kaufman, "Interventions for intimate partner violence: review and implications for evidence-based practice," Professional Psychology: Research \& Practice, vol. 40, no. 3, pp. 223-233, 2009.

[22] P. Tjaden and N. Thoennes, "Prevalence and consequences of male-to-female and female-to-male intimate partner violence as measured by the national violence against women survey," Violence Against Women, vol. 6, no. 2, pp. 142-161, 2000.

[23] C. N. Wathen and H. L. MacMillan, "Interventions for violence against women: scientific review," Journal of the American Medical Association, vol. 289, no. 5, pp. 589-600, 2003. 
[24] A. E. Bonomi, M. L. Anderson, R. J. Reid, F. P. Rivara, D. Carrell, and R. S. Thompson, "Medical and psychosocial diagnoses in women with a history of intimate partner violence," Archives of Internal Medicine, vol. 169, no. 18, pp. 1692-1697, 2009.

[25] M. M. Cohen, B. Schei, D. Ansara, R. Gallop, N. Stuckless, and D. E. Stewart, "A history of personal violence and postpartum depression: is there a link?" Archives of Women's Mental Health, vol. 4, no. 3, pp. 83-92, 2002.

[26] A. L. Coker, P. H. Smith, L. Bethea, M. R. King, and R. E. McKeown, "Physical health consequences of physical and psychological intimate partner violence," Archives of Family Medicine, vol. 9, no. 5, pp. 451-457, 2000.

[27] J. R. Jaeger, D. Spielman, P. F. Cronholm, S. Applebaum, and W. C. Holmes, "Screening male primary care patients for intimate partner violence perpetration," Journal of General Internal Medicine, vol. 23, no. 8, pp. 1152-1156, 2008.

[28] K. V. Rhodes and T. J. Iwashyna, "Male perpetrators of intimate partner violence: support for health care interventions targeted at level of risk," Behaviour Change, vol. 26, no. 3, pp. 174-189, 2009.

[29] M. C. Black, K. C. Basile, M. J. Breiding et al., The National Intimate Partner and Sexual Violence Survey (NISVS): 2010 Summary Report, US Department of Health and Human Services, CDC, National Center for Injury Prevention and Control, Atlanta, Ga, USA, 2011.

[30] J. K. Daday, L. M. Broidy, and C. S. Crandall, "Emergency department utilization among victims and offenders involved in non-lethal violence," Social Science and Medicine, vol. 66, no. 5, pp. 1197-1203, 2008.

[31] C. C. Mechem, F. S. Shofer, S. S. Reinhard, S. Hornig, and E. Datner, "History of domestic violence among male patients presenting to an urban emergency department," Academic Emergency Medicine, vol. 6, no. 8, pp. 786-791, 1999.

[32] M. B. Phelan, L. K. Hamberger, C. E. Guse, S. Edwards, S. Walczak, and A. Zosel, "Domestic violence among male and female patients seeking emergency medical services," Violence and Victims, vol. 20, no. 2, pp. 187-206, 2005.

[33] M. R. Rand and K. Strom, Violence-Related Injuries Treated in Hospital Emergency Departments, Bureau of Justice Statistics, Washington, DC, USA, 1997.

[34] P. C. Alexander, E. Morris, A. Tracy, and A. Frye, "Stages of change and the group treatment of batterers: a randomized clinical trial," Violence and Victims, vol. 25, no. 5, pp. 571-587, 2010.

[35] L. F. Mbilinyi, C. Neighbors, D. D. Walker et al., "A telephone intervention for substance-using adult male perpetrators of intimate partner violence," Research on Social Work Practice, vol. 21, no. 1, pp. 43-56, 2011.

[36] P. H. Musser, J. N. Semiatin, C. T. Taft, and C. M. Murphy, "Motivational interviewing as a pregroup intervention for partner-violent men," Violence and Victims, vol. 23, no. 5, pp. 539-557, 2008.

[37] K. Scott, C. King, H. McGinn, and N. Hosseini, "Effects of motivational enhancement on immediate outcomes of batterer intervention," Journal of Family Violence, vol. 26, no. 2, pp. 139149, 2011.

[38] S. M. Stith, D. B. Smith, C. E. Penn, D. B. Ward, and D. Tritt, "Intimate partner physical abuse perpetration and victimization risk factors: a meta-analytic review," Aggression and Violent Behavior, vol. 10, no. 1, pp. 65-98, 2004.
[39] E. M. Woodin and K. D. O'Leary, "A brief motivational intervention for physically aggressive dating couples," Prevention Science, vol. 11, no. 4, pp. 371-383, 2010.

[40] M. Straus, "Women's violence toward men is a serious social problem," in Current Controversies on Family Violence, D. Loseke, R. Gelles, and M. Cavanaugh, Eds., pp. 55-77, Sage Publications, Thousand Oaks, Calif, USA, 2005.

[41] J. A. Schumacher and K. E. Leonard, 'Husbands' and wives' marital adjustment, verbal aggression, and physical aggression as longitudinal predictors of physical aggression in early marriage," Journal of Consulting and Clinical Psychology, vol. 73, no. 1, pp. 28-37, 2005.

[42] L. Dowd and P. A. Leisring, "A framework for treating partner aggressive women," Violence \& Victims, vol. 23, no. 2, pp. 249263, 2008.

[43] Centers for Disease Control and Prevention (CDC) and National Center for Health Statistics, Rates of Discharges from Short-Stay Hospitals, by Age and First-Listed Diagnosis: United States, 2010, Centers for Disease Control and Prevention (CDC), National Center for Health Statistics, Hyattsville, Md, USA, 2013.

[44] National Center for Health Statistics and Centers for Disease Control and Prevention, National Hospital Ambulatory Medical Care Survey: 2010 Emergency Department Summary Tables, National Center for Health Statistics and Centers for Disease Control and Prevention, 2013.

[45] US Census Bureau, "Profile of general population and housing characteristics: 2010 demographic profile data, United States," 2012, http://factfinder.census.gov/faces/tableservices/jsf/pages/ productview.xhtml? src $=$ bkmk.

[46] U.S. Census Bureau, Poverty Status in the Past 12 Months: 2010 American Community Survey 1-Year Estimates, U.S. Census Bureau, 2012, http://factfinder2.census.gov/faces/tableservices/ jsf/pages/productview.xhtml?pid=ACS_10_1YR_S1701\&prodType $=$ table.

[47] Federal Bureau of Investigation, Crime in the United States: number of crimes per 100,000 inhabitants, 2010, http://www .dartmouthatlas.org/data/table.aspx?loc=184\&loct=3\&ind $=135$.

[48] Dartmouth Atlas of Health Care, "Acute care hospital beds per 1,000 residents," 2014, http://www.dartmouthatlas.org/data/ table. aspx ind $=135 \& \mathrm{tf}=8 \& \mathrm{ch}=\&$ loc $=\&$ loct $=3 \& \mathrm{fmt}=160$.

[49] Dartmouth Atlas of Health Care, Acute Care Hospital Beds Per 1,000 Residents (2006, Hospital Referral Region), Dartmouth Atlas of Health Care, 2014.

[50] C. L. Kothari and K. V. Rhodes, "Missed opportunities: emergency department visits by police-identified victims of intimate partner violence," Annals of Emergency Medicine, vol. 47, no. 2, pp. 190-199, 2006.

[51] M. P. Koss, “The impact of crime victimization on women's medical use," Journal of Women's Health, vol. 2, no. 1, pp. 67-72, 1993.

[52] Y. C. Ulrich, K. C. Cain, N. K. Sugg, F. P. Rivara, D. M. Rubanowice, and R. S. Thompson, "Medical care utilization patterns in women with diagnosed domestic violence," American Journal of Preventive Medicine, vol. 24, no. 1, pp. 9-15, 2003.

[53] R. MacMillan and C. Kruttschnitt, "Patterns of violence against women: risk factors and consequences," NCJ 208346, US Department of Justice, National Institute of Justice, Washington, DC, USA, 2005.

[54] M. S. Straus, S. L. Hamby, S. Boney-McCoy, and D. B. Sugarman, "The revised conflict tactics scales (CTS2)," Journal of Family Issues, vol. 17, no. 3, pp. 283-316, 1996. 
[55] D. J. Whitaker, T. Haileyesus, M. Swahn, and L. S. Saltzman, "Differences in frequency of violence and reported injury between relationships with reciprocal and nonreciprocal intimate partner violence," American Journal of Public Health, vol. 97, no. 5, pp. 941-947, 2007.

[56] A. R. Klein, "Practical implications of current domestic violence research: for law enforcement, prosecutors and judges," NCJ 225722, Department of Justice, National Institute of Justice, Washington, DC, USA, 2009.

[57] H. D. Nelson, C. Bougatsos, and I. Blazina, "Screening women for intimate partner violence: a systematic review to update the U.S. Preventive Services Task Force recommendation," Annals of Internal Medicine, vol. 156, no. 11, pp. 796-808, 2012.

[58] J. W. Davis, S. N. Parks, K. L. Kaups, L. D. Bennink, and J. F. Bilello, "Victims of domestic violence on the trauma service: unrecognized and underreported," Journal of Trauma-Injury, Infection \& Critical Care, vol. 54, no. 2, pp. 352-355, 2003.

[59] P. Gendreau, T. Little, and C. Goggin, "A meta-analysis of the predictors of adult offender recidivism: what works!"” Criminology, vol. 34, no. 4, pp. 575-607, 1996.

[60] A. Holtzworth-Munroe, "A typology of men who are violent toward their female partners: making sense of the heterogeneity in husband violence," Current Directions in Psychological Science, vol. 9, no. 4, pp. 140-143, 2000.

[61] V. Wu, H. Huff, and M. Bhandari, "Pattern of physical injury associated with intimate partner violence in women presenting to the emergency department: a systematic review and metaanalysis," Trauma, Violence, \& Abuse, vol. 11, no. 2, pp. 71-82, 2010.

[62] C. A. Gallagher, "Injury recurrence among untreated and medically treated victims of violence in the USA," Social Science and Medicine, vol. 60, no. 3, pp. 627-635, 2005.

[63] D. M. Melnick, R. F. Maio, F. C. Blow et al., "Prevalence of domestic violence and associated factors among women on a trauma service," Journal of Trauma, vol. 53, no. 1, pp. 33-37, 2002.

[64] S. Catalano, Intimate Partner Violence in the United States, US Department of Justice, Bureau of Justice Statistics, Washington, DC, USA, 2007. 


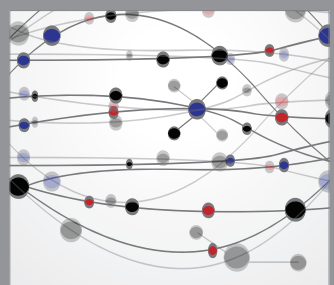

The Scientific World Journal
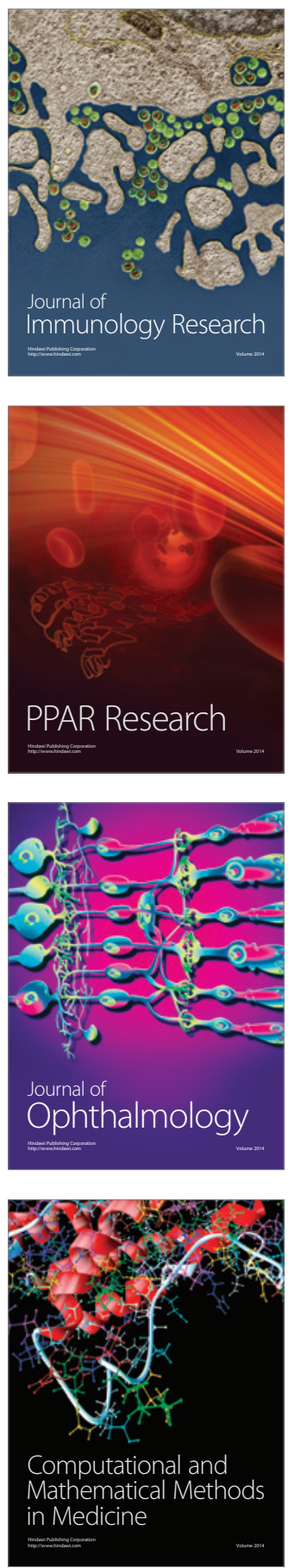

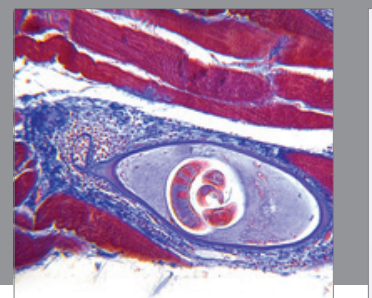

Gastroenterology

Research and Practice
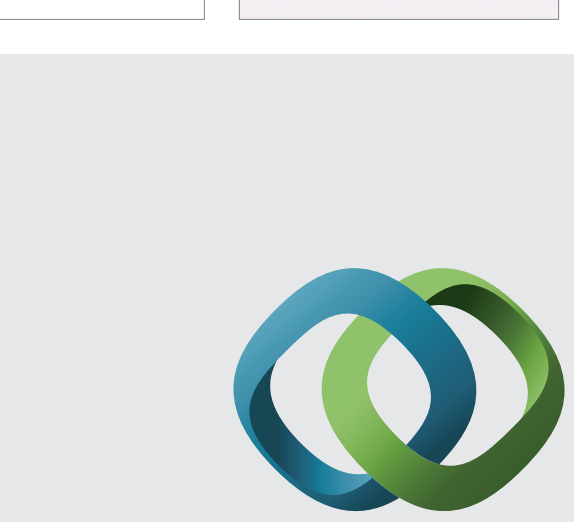

\section{Hindawi}

Submit your manuscripts at

http://www.hindawi.com
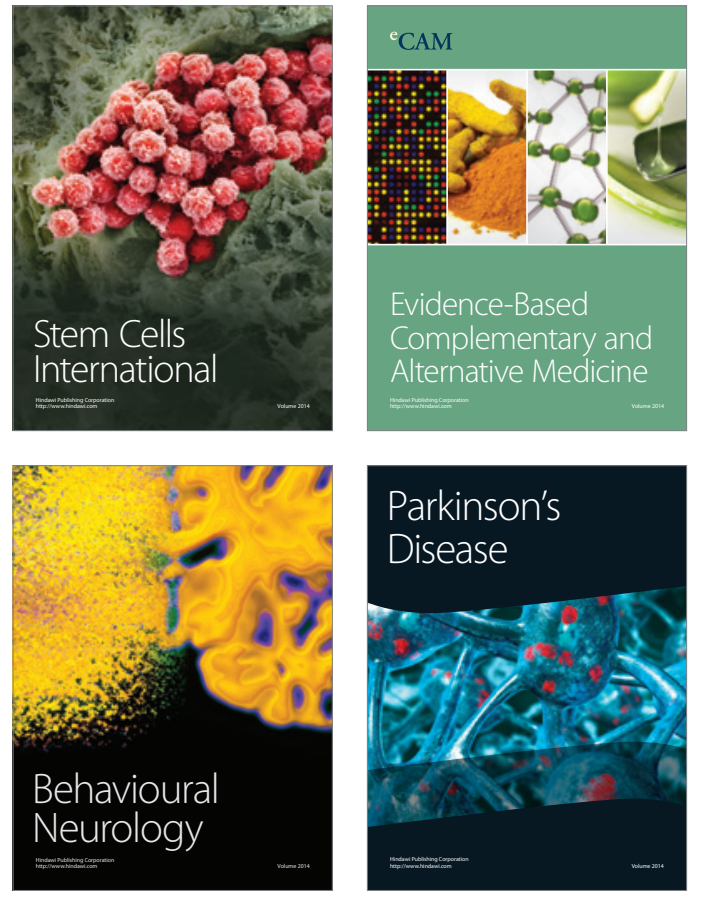
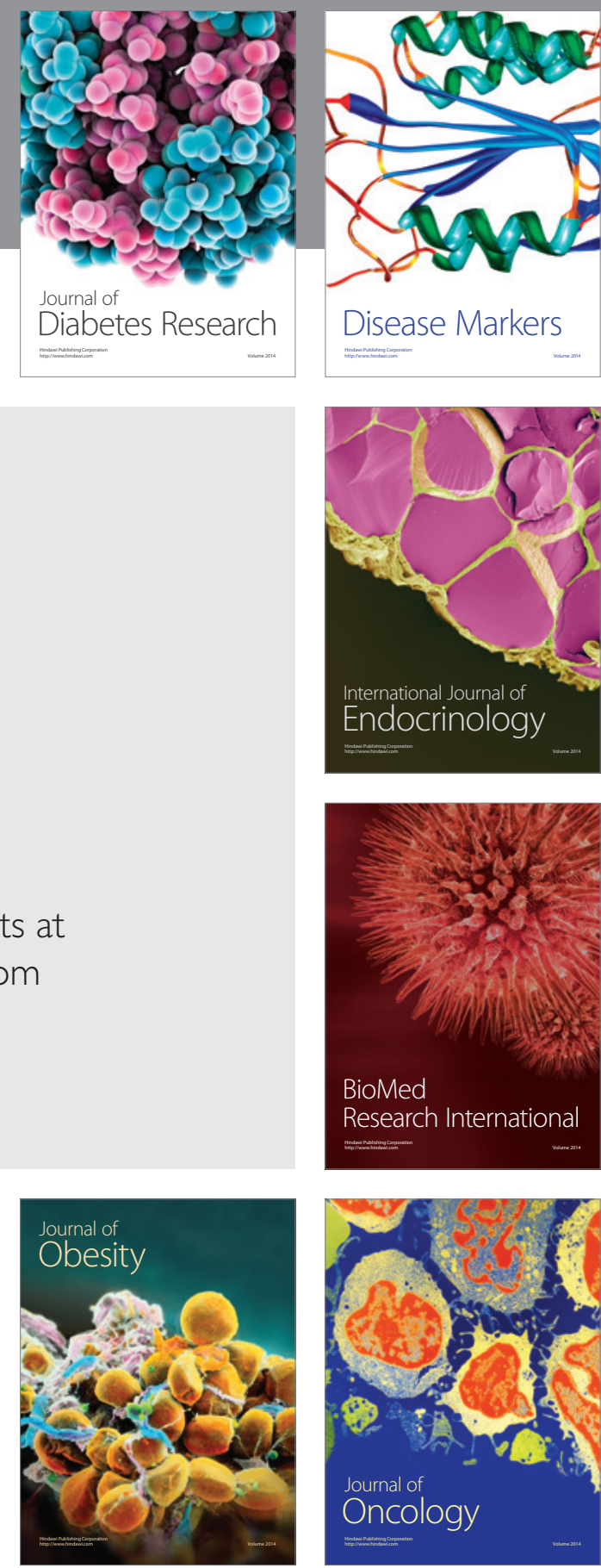

Disease Markers
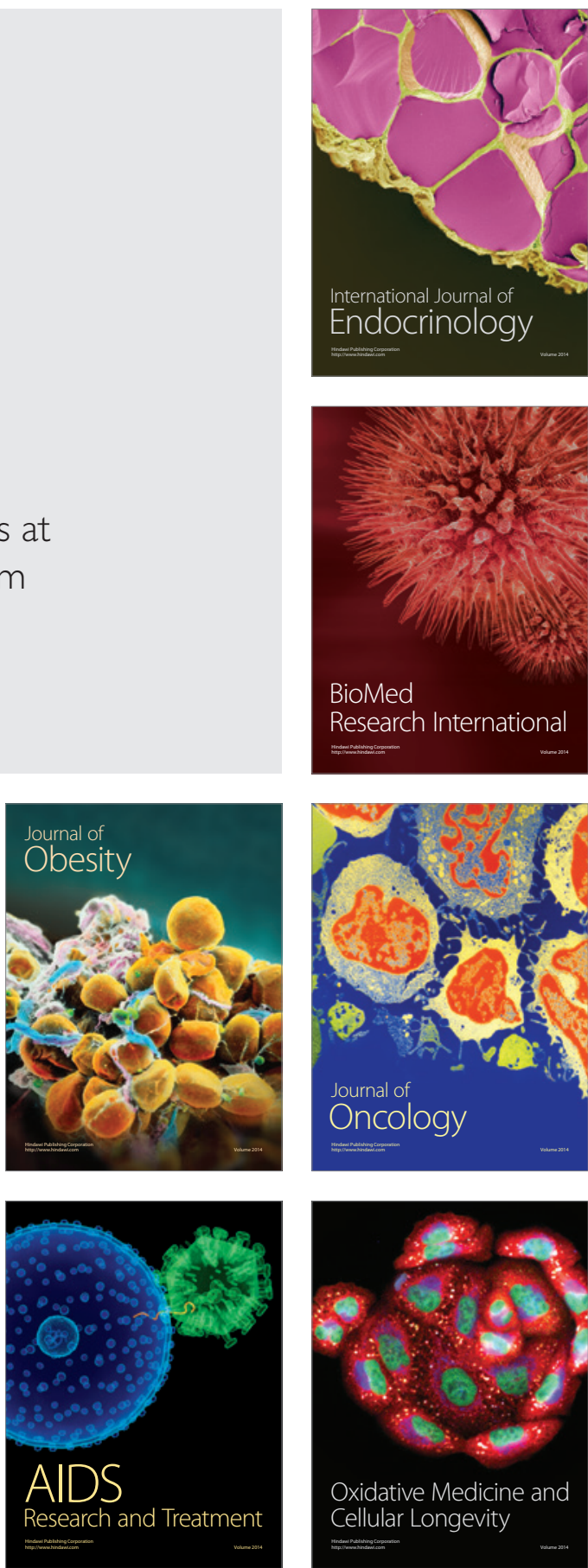